\title{
A computer simulation model for cost-effectiveness analysis of mass screening for Type 2 diabetes mellitus
}

\author{
Tony Hsiu-Hsi Chen ${ }^{\mathrm{a}, *}$, Ming-Fang Yen ${ }^{\mathrm{a}}$, Tao-Hsin Tung ${ }^{\mathrm{b}}$ \\ a Graduate Institute of Epidemiology, College of Public Health, National Taiwan University, Taipei, Taiwan, ROC \\ ${ }^{\mathrm{b}}$ Community Medicine Research Center and Institute of Public Health, National Yang-Ming University, Taipei, Taiwan, ROC
}

\begin{abstract}
The cost-effectiveness analysis of mass screening for Type 2 diabetes mellitus (DM) was performed to elucidate whether, who and how often it should be conducted in Taiwan. A series of Markov process was developed to model the disease natural history of Type 2 DM. A hypothetical cohort with 30000 residents aged over 30 years in Taiwan was randomly assigned to three arms of screening regimes, biennial, five-yearly and the control group. A Monteo Carol computer simulation was performed to calculate effectiveness of two screening regimes compared with the control group. Direct costs and utilities were incorporated to each corresponding state to calculate the incremental costs per life-years gained and per quality-adjusted life-years (QALYs) for biennial and five-yearly screening regimes. The incremental costs for biennial screening regime were estimated at $\$ 26750$ per life-year gained, and $\$ 17833$ per QALY. The corresponding figures for five-yearly screening regime were $\$ 10531$ per life-year gained and $\$ 17113$ per QALY. The incremental costs per life-year gained and per QALY increase with age, ranging from $\$ 17238$ for aged $30-39$ years to $\$ 54700$ for aged over 70 years and from $\$ 9193$ to 36467 , respectively. In conclusion, mass screening for Type 2 DM, especially in younger subjects, with 5-year inter-screening interval is cost-effective in Taiwan. (C) 2001 Elsevier Science Ireland Ltd. All rights reserved.
\end{abstract}

Keywords: Cost-effectiveness analysis; Type 2 diabetes mellitus; Mass screening; Markov model; Monte Carol computer simulation

\section{Introduction}

As the prevalence of Type 2 diabetes mellitus (DM) was estimated as $6-12 \%$ in Taiwan [1,2] and Type $2 \mathrm{DM}$, if undiagnosed before the occurrence of clinical symptoms, would lead to microvascular complications, macro-vascular complications, and death, it is timely to consider whether a

* Corresponding author. Tel.: + 886-2-23587620; fax: + 886-2-23587707.

E-mail address: stony@episerv.cph.ntu.edu.tw (T.H.-H. Chen). mass screening for Type $2 \mathrm{DM}$ is worthwhile. However, the efficacy of mass screening for Type $2 \mathrm{DM}$ in reducing complications or deaths has never been firmly demonstrated in populationbased randomized trials. The efficacy of mass screening for Type $2 \mathrm{DM}$ is highly dependent on many parameters including the natural history of disease process, the performance of screening tool, and the appropriate follow-up protocol. Kuo et al. [3] estimated a 50\% mortality reduction from non-insulin-dependent diabetes mellitus based on a Markov model approach. However, complications of Type $2 \mathrm{DM}$ were not considered 
in this study. From an economical viewpoint, although mass screening brings about health benefits but a slew of costs will be incurred as a result of expenditure from mass screening. Consequently, whether mass screening is cost-effective is dependent on whether health benefits can outweigh the extra cost due to mass screening. A recent study from CDC Diabetes Cost-Effectiveness Study [4] using a computer simulation model also showed the effectiveness of opportunistic screening for Type $2 \mathrm{DM}$ in reducing the life-time incidence of major micro-vascular complications, which resulted in gaining both life-years and quality-adjusted life-years (QALYs). Since the major focus of this study is opportunistic screening rather than the organized mass screening for Type $2 \mathrm{DM}$ that is targeted to apparently healthy subject from the community. It is uncertain whether these results or models can be directly applied to mass screening.

To the best of our knowledge, the study on economic evaluation for mass screening for Type $2 \mathrm{DM}$ has not been conducted yet. In addition to whether screening for Type $2 \mathrm{DM}$ is worthwhile, two questions are often asked in screening scenario. These include who should be screened and how frequently one should be screened. The purposes of this study are, therefore, to use a computer simulation model to:

1. develop the disease natural history of Type 2 DM from normal, onset of DM, the manifestation of clinical complications, and finally to death;

2. quantify the efficacy of early detection of Type $2 \mathrm{DM}$ in slowing or reducing the progression of major complications based on 1 ;

3. evaluate the effect of inter-screening interval and age at the start of screen on slowing or reducing the progression of major complications or deaths based on 1 ;

4. compare the cost and effectiveness of an organized screening regime with the control group without screening; and

5. assess the cost-effectiveness of Type $2 \mathrm{DM}$ screening by age-specific groups and different inter-screening interval.

\section{Subjects and methods}

A Markov Monte Carol simulation model was developed to evaluate the efficacy of Type $2 \mathrm{DM}$ screening. The model was divided into four parts as follows.

\subsection{Disease natural history model}

A Markov model was developed to simulate the disease natural history of Type 2 DM from normal, onset of DM, clinical complications, and finally, to deaths. The make-up of demographic characteristics in this cohort was identical to the residents in Taiwan according to vital statistics in 1995. Life-table information was also used to adjust for competing causes of deaths while the disease natural history of DM was simulated. The incidence of Type 2 DM from normal to onset of DM was $1.1 \%$, estimated by Kuo et al. [3]. Disease progression modules from onset of DM to complications include three parts: Retinopathy, Nephropathy, and Neuropathy. Clinical definitions of health state for three major micro-vascular complications refer to Eastman et al. [5]. Transition parameters used for simulating disease progression refer to Eastman et al. [5], Javitt at al. [6], Harris et al. [7], Klein et al. [8], Ballard et al. [9], Humphrey et al. [10], USRD [11], Dyck et al. [12], Humphrey et al. [13], and CDC-DCS group [4]. Table 1 shows the baseline estimates of these parameters. It should be noted that state transitions for three complications vary by the duration of DM. The incidence and mortality rates of cardiovascular disease, estimated from the Framingham Heart Study [14], are a function of age, sex, systolic blood pressure, total cholesterol, high-density lipid level and smoking. The distributions with respect to these variables are adjusted to represent the composition of residents in Taiwan.

\subsection{Screening strategies}

We assess how the above disease natural history can be altered by screening policies, including two- and five-yearly regimes. A hypothetical cohort $(N=30000)$ with subjects aged over 30 years 
was randomly assigned to two screened arms and one control arm. The screening program lasts for 10 years. Numbers of screening rounds for twoand five-yearly regimes are six and three, respectively. Each DM case after diagnosis is followed over 30 years or until death to monitor the progression of complications or death.

\subsection{Treatment effectiveness}

We assume early diagnosis and treatment can control glycemic level and further reduce microand macro-vascular complications. We also assume such glycemic control leading to the reduction of adverse consequence varies by the duration of diabetes and types of complications. Parameters with treatment efficacy refer to Eastman et al. [5], and UKPDS [15]. These estimates were modified according to Chen et al. [16].

\subsection{Cost}

Direct costs estimated in this study include screening cost [17], routine treatment on glycemic control $[16,18-20]$, treatment on micro-vascular complication [17,21-24], and treatment on macro-vascular disease [25]. Indirect costs are not considered in this study.

\section{Table 1}

Baseline values for estimates of cost-effectiveness analysis using a computer simulation model

\begin{tabular}{lll}
\hline Variable & Baseline values & References \\
\hline $\begin{array}{l}\text { 1. Incidence of Type 2 DM } \\
\text { 2. Transition rates of } \\
\text { complication }\end{array}$ & 0.0107 & {$[3]$} \\
$\begin{array}{l}\text { (1) Retinopathy } \\
\text { NDR } \rightarrow \text { non-proliferative }\end{array}$ & 0.0730 & {$[6,7]$} \\
$\begin{array}{l}\text { Non-proliferative } \\
\rightarrow \text { proliferative }\end{array}$ & 0.0103 & \\
$\begin{array}{l}\text { Non-proliferative } \rightarrow \text { macula } \\
\text { edema }\end{array}$ & 0.1928 & \\
$\begin{array}{l}\text { Proliferative } \rightarrow \text { blindness } \\
\text { Macula edema } \rightarrow \text { blindness }\end{array}$ & 0.0148 & \\
\end{tabular}

Table 1 (Continued)

\begin{tabular}{|c|c|c|}
\hline Variable & Baseline values & References \\
\hline $\begin{array}{l}\text { (2) Nephropathy \& CVD } \\
\text { mortality }\end{array}$ & & {$[8-11]$} \\
\hline No nephropathy $\rightarrow$ MA & 0.0267 & \\
\hline $\mathrm{MA} \rightarrow$ proteinunia & 0.1572 & \\
\hline Proteinunia $\rightarrow$ ESRD $^{\mathrm{b}}$ & 0.0042 & \\
\hline $\mathrm{ESRD} \rightarrow \mathrm{CVD}$ & 0.5000 & \\
\hline $\mathrm{CVD} \rightarrow$ death & 0.2000 & \\
\hline (3) Neuropathy & & {$[12,13]$} \\
\hline $\begin{array}{l}\text { No } \\
\text { neuropathy } \rightarrow \text { symptomatic } \\
\text { neuropathy }\end{array}$ & 0.0144 & \\
\hline $\begin{array}{l}\text { Symptomatic } \\
\text { neuropathy } \rightarrow \mathrm{LEA}^{\mathrm{c}}\end{array}$ & 0.0280 & \\
\hline CVD morbidity & $\begin{array}{l}\text { Logistic } \\
\text { regression }\end{array}$ & {$[14]$} \\
\hline $\begin{array}{l}\text { CVD mortality rate for } \\
\text { non-ESRD patient }\end{array}$ & 0.02 & \\
\hline 3. Cost & & \\
\hline (1) Screening & & {$[17]$} \\
\hline Fasting plasma glucose test & 28 & \\
\hline Hemoglobin test & 38 & \\
\hline Oral glucose tolerance test & 106 & \\
\hline \multicolumn{3}{|l|}{ (2) Routine treatment drugs } \\
\hline Drugs & & {$[17-20]$} \\
\hline $\begin{array}{l}\text { Insulin and oral agents } \\
(\text { duration } \geqslant 10)\end{array}$ & 714 per year & \\
\hline Insulin $(0<$ duration $<10)$ & 513 per year & \\
\hline Self-testing & 222 per year & \\
\hline $\begin{array}{l}\text { Outpatient services insulin } \\
\text { users }\end{array}$ & 618 per year & \\
\hline Case management & 121 per year & \\
\hline (3) Complications & & {$[6,17,22-25]$} \\
\hline $\begin{array}{l}\text { Blindness (direct medical } \\
\text { cost) }\end{array}$ & 1997 per year & \\
\hline Photocoagulation treatment & 2682 (life-time) & \\
\hline Eye examination & 84 & \\
\hline Neurologic examination & 130 & \\
\hline Renal examination & 1129 & \\
\hline End-stage renal disease & 68131 per year & \\
\hline $\begin{array}{l}\text { Lower extremity } \\
\text { amuputation }\end{array}$ & $31139 /$ op & \\
\hline Cardiovascular disease & 2757 per year & \\
\hline 4. Utility for $Q A L Y S$ & & {$[17,23,26]$} \\
\hline No Type 2 diabetes & 1.00 & \\
\hline $\begin{array}{l}\text { Screen-detected Type } 2 \\
\text { diabetes }\end{array}$ & 0.95 & \\
\hline Blindness & 0.69 & \\
\hline ESRD & 0.61 & \\
\hline LEA & 0.80 & \\
\hline Discount rate & $3 \%$ & \\
\hline
\end{tabular}

a Vary by duration. The current figure represents $0-5$ years.
b Vary by duration. The current figure represents $0-12$ years.
${ }^{c}$ Vary by duration. The current figure represents $0-9$ years. 
Table 2

Cumulative incidence rate of micro-vascular complications (effectiveness) by different screening regimes

\begin{tabular}{|c|c|c|c|}
\hline $\begin{array}{l}\text { Screening } \\
\text { regimes }\end{array}$ & Blindness & ESRD & LEA \\
\hline Two-yearly & $3.06 \%(30 \%)$ & $0.19 \%(65 \%)$ & $0.97 \%(33 \%)$ \\
\hline Five-yearly & $3.13 \%(28 \%)$ & $0.19 \%(65 \%)$ & $0.99 \%(31 \%)$ \\
\hline Control group & $4.37 \%$ & $0.54 \%$ & $1.43 \%$ \\
\hline
\end{tabular}

\subsection{Effectiveness}

Outcome measures are life-years gained and QALYs. A utility value of 1.0 is assumed for each year of life lived without diabetes. A utility value of 0.95 is assigned for subjects with DM detected by screen but without further complication. The utility values for blindness [26], ESRD [17] and LEA [23] are $0.69,0.61$ and 0.8 , respectively.

\subsection{Remarks}

Costs and benefits are discounted at 3\%, and costs are expressed in US\$.

\section{Results}

Simulated results yield 49.40, 49.86 and 54.15 of average age at diagnosis for biennial and fiveyearly screening regimes, and the control group, respectively. Table 2 shows cumulative incidence rates of micro- and macro-vascular complications by screening regimes after 30 years of follow-up.

Table 3

Cost-effectiveness analysis of mass screening for Type 2 diabetes by screening regimes

\begin{tabular}{|c|c|c|}
\hline Cost \& outcome & Two-yearly & Five-yearly \\
\hline $\begin{array}{l}\text { Increased cost due to screen } \\
\text { (in \$) }\end{array}$ & 2140 & 1369 \\
\hline Life-years gained & 0.08 & 0.08 \\
\hline QALYs gained & 0.12 & 0.13 \\
\hline $\begin{array}{l}\text { Incremental cost per } \\
\text { additional life-years (in \$) }\end{array}$ & 26750 & 17113 \\
\hline $\begin{array}{l}\text { Incremental cost per } \\
\text { QALYs (in \$) }\end{array}$ & 17833 & 10531 \\
\hline
\end{tabular}

No significant difference of reducing complications was found between two- and five-yearly regimes. Compared with the control group, preventive fractions of blindness, ESRD, and LEA due to biennial screening regime were estimated as 30,65 , and $33 \%$ respectively. The corresponding figures for five-yearly regime were 28,65 , and $31 \%$ respectively. However, there is a small difference between two screening regimes with respect to the efficacy of reducing complications.

Regarding cost-effectiveness analysis, Table 3 shows cost due to screen, life-years gained, QALYs gained, incremental cost per life-year gained and incremental cost per QALY for two screening regimes as compared with the control group. Costs due to screen for biennial and fiveyearly screening regimes were calculated as $\$ 2140$ and 1369, respectively. Life-years gained due to screen are 0.08 in both screen programs. QALYs gained due to screen are 0.12 and 0.13 for biennial and five-yearly screening regimes. The incremental costs for biennial screening regime were estimated at $\$ 26750$ per life-year gained, and $\$ 17833$ per QALY. The corresponding figures for five-yearly screening regime were $\$ 10531$ per life-year gained and \$17113 per QALY. Table 4 shows age-specific results of the efficacy and cost-effectiveness of five-yearly mass screening. It can be seen that although the absolute cost of screening younger cohort was larger than the older cohort, extra cost would be offset with additional life-years. Table 4 also shows the extra QALYs gained due to fiveyearly screening regime decrease with age. Lifeyears gained in the younger cohort were approximately five times longer than those in the older cohort. The incremental costs per life-year gained for age groups 30-39, 40-49, 50-59, 6069 and $70+$ for five-yearly screening regime were estimated as $\$ 17238,11400,11842,18788$, and 54700 , respectively. The corresponding figures with respect to QALYs are \$9193, 7600, 8881, 16700 , and 36467 , respectively.

\section{Discussion}

A computer simulation model was performed to assess the cost-effectiveness and the cost-util- 
Table 4

Cumulative incidence rate differences of five-yearly screening regime and cost-effectiveness analysis by age groups

\begin{tabular}{|c|c|c|c|c|c|}
\hline & $30-39$ & $40-49$ & $50-59$ & $60-69$ & $70+$ \\
\hline Blindness $(\%)$ & 1.61 & 1.49 & 1.14 & 0.61 & 0.34 \\
\hline ESRD $(\%)$ & 0.47 & 0.41 & 0.26 & 0.12 & 0.06 \\
\hline LEA $(\%)$ & 0.59 & 0.55 & 0.40 & 0.16 & 0.05 \\
\hline Increased cost due to screen (in \$) & 1379 & 1368 & 1421 & 1503 & 1094 \\
\hline Life-years gained & 0.08 & 0.12 & 0.12 & 0.08 & 0.02 \\
\hline Incremental cost per QALY (in \$) & 9193 & 7600 & 8881 & 16700 & 36467 \\
\hline
\end{tabular}

ity analysis of mass screening for Type 2 DM that is targeted to general population by simulating the disease natural history of Type 2 DM from normal, onset of Type 2 DM, micro-vascular or macro-vascular complications and finally, to death with the incorporation of cost and utility corresponding to each state. Economic evaluation with respect to the effect of inter-screening interval on the reduction of complication is also examined. The incremental costs were estimated at $\$ 10531$ per life-year gained and $\$ 17113$ per QALY gained. Compared with the corresponding figures for breast cancer screening with mammography (\$3400-83830 per life-year gained), cervical cancer screening (\$50000 life-year gained) and hypertension screening for women aged over 20 years $(\$ 87000)$, five-yearly mass screening for Type 2 DM seems cost-effective. In addition, mass screening for Type $2 \mathrm{DM}$ in younger cohort is more cost-effective than in the older cohort.

In contrast to results of opportunistic screening for patients with Type 2 DM, mass screening for Type $2 \mathrm{DM}$ targeted to general population is rather cost-effective. Results from CDC Diabetes Cost-Effectiveness Group showed that the incremental cost of opportunistic screening among all persons aged 25 years or older was estimated at $\$ 236449$ per life-year gained and $\$ 56649$ per QALY gained that are higher than the estimates from mass screening. The reason is that extra cost incurred in mass screening for general population is offset with life-years gained. Life-years gained and QALYs gained due to screen in our five-yearly mass screening program are 0.08 and 0.13 whereas the corresponding figures in opportunistic screening are only 0.02 and 0.08 .

It should be noted that the benefit of mass screening for Type 2 DM may be underestimated in this study partly due to the benefit of early detection in reducing macro-vascular diseases was not investigated and partly due to the benefit of early detection of impaired glucose tolerance was not modeled in the disease natural history. There are several other limitations to this study. First, since indirect costs were not included in this study, it is difficult to apply the results of cost-effectiveness analysis to the perspective of society. Second, we assume glycemic control is based on complete follow-up. However, whether the logistic of follow-up can be achieved is rather skeptical. Ongoing researches should be conducted to investigate this problem. Third, the screening method used in this study is based on fasting blood sugar. However, one may assess whether glycated hemoglobin, an important indicator for glycemic control, can be used for mass screening for Type $2 \mathrm{DM}$.

In conclusion, a mathematical computer simulation model was proposed to perform the cost-effectiveness analysis of mass screening for Type 2 DM. Results show mass screening for Type $2 \mathrm{DM}$ with 5 -year inter-screening interval in countries with $6-12 \%$ prevalence is cost-effective as compared with opportunistic screening. 


\section{References}

[1] P. Chou, H.H. Chen, K.J. Hsiao, Community-based epidemiological study on diabetes in Pu-Li, Taiwan, Diab. Care 15 (1992) 81-89.

[2] P. Chou, M.J. Liao, H.S. Kuo, K.J. Hsiao, S.T. Tsai, A population survey on the prevalence of diabetes in KinHu, Kinmen, Diab. Care 17 (1994) 1055-1058.

[3] H.S. Kuo, H.J. Chang, P. Chou, L. Teng, T.H.H. Chen, A Markov chain model to assess the efficacy of screening for non-insulin dependent diabetes mellitus (NIDDM), Inter. J. Epidemiol. 28 (1999) 233-240.

[4] CDC Diabetes Cost-Effectiveness Study Group. The cost-effectiveness of screening for Type 2 Diabetes, J. Am. Med. Assoc. 280 (1998) 1757-1763.

[5] R.C. Eastman, J.C. Javitt, W.H. Herman, et al., Model of complications of NIDDM, Diab. Care 20 (1997) 725734.

[6] J.C. Javitt, L.P. Aiello, Y. Chiang, R.L. Ferris III, J.K. Canner, S. Greenfield, Preventive eye care in people with diabetes is cost-saving to the federal government: implications for health-care reform, Diab. Care 17 (1994) 909917.

[7] M.I. Harris, R. Klein, T.A. Welborn, M.W. Knuiman, Onset of NIDDM occurs at least 4-7 years before clinical diagnosis, Diab. Care 15 (1992) 815-819.

[8] R. Klein, B.E.K. Klein, S.E. Moss, Prevalence of microalbuminurial in older-onset diabetes, Diab. Care 16 (1993) 1325-1330.

[9] D.J. Ballard, L.L. Humphrey, J.P.P. Frohnert, et al., Epidemiology of persistent proteinurial in type II diabetes mellitus, Diabetes 37 (1988) 405-412.

[10] L.L. Humphrey, D.J. Ballard, P.P. Frohnert, C.P. Chu, W.M. O'Fallon, P.J. Palumbo, Chronic renal failure in non-insulin-dependent diabetes mellitus, Ann. Intern. Med. 111 (1989) 788-796.

[11] US Renal Data System (USRDS) 1994 Annual Data Report, The National Institutes of Health, National Institute of Diabetes and Digestive and Kidney Disease, Bethesda, MD, 1994, Appendix D. 17.

[12] P.J. Dyck, K.M. Dratz, J.L. Karnes, et al., The prevalence by staged severity of various types of diabetic neuropathy, retinopathy, and nephropathy in a population-based cohort: the Rochester Diabetic Neuruopathy Study, Neurology 43 (1993) 817-824.
[13] L.L. Humphrey, P.J. Palumbo, M.A. Butters, et al., The contribution of non-insulin-dependent diabetes to lowerextremity amputation in the community, Arch. Intern. Med. 154 (1994) 885-892.

[14] K.M. Anderson, P.M. Odell, P.W.F. Wilson, W.B. Kannel, Cardiovascular disease risk profiles, Am. Heart J. 121 (1990) 293-298.

[15] UK Prospective Diabetes Study Group. UK Prospective Diabetes Study (UKPDS), VIII: study design, progress and performance. Diabetologia 34 (1991) 877-890.

[16] N.S. Chen, C.S. Kao, C.C. Fu, C.J. Chen, T.Y. Tai, Incidence and progression of diabetic retinopathy among non-insulin-dependent diabetic subjects: a 4-year followup, Int. J. Epidemiol. 24 (1995) 787-795.

[17] Diabetes Control and Complications Trial Research Group, Lifetime benefits and costs of intensive therapy as practiced in the diabetes control and complications trial, J. Am. Med. Assoc. 276 (1996) 1409-1415.

[18] C. Abraraira, J.A. Colwell, F.Q. Nuttall, et al., Veterans affairs cooperative study on glycemic control and complications in Type 2 Diabetes (VACSDM), Diab. Care 18 (1995) 1113-1123.

[19] Medical Economics, Red Book, Montvale, NJ. Medical Economics Co, 1996.

[20] National Health Interview Survey [database on CDROW], Washington, DC. US Government Printing Office, 1993.

[21] J.C. Javitt, L.P. Aiello, Y. Chiang, R.L. Ferris III, J.K. Canner, S. Greenfield, Preventive eye care in people with diabetes is cost-saving to the federal government: implications for health-care reform, Diab. Care 17 (1994) 909917.

[22] Health Care Financing Administration, Research Report. End Stage Renal Disease, 1994. Baltimore, MD, Health Care Financing Administration, 1996.

[23] M.H. Eckman, S. Greenfield, W.C. Mackey, et al., Foot infections in diabetic patients, J. Am. Med. Assoc. 273 (1995) 721.

[24] S.W. Balkin, Lower limb amputation and the diabetic foot, J. Am. Med. Assoc. 273 (1995) 185.

[25] American Heart Association, Heart and Stroke Facts. Statistical Supplement. Dallas, Tex. American Heart Association, 1995.

[26] E.J. Dasbach, D.F. Fyback, J.R. Thornbury, Health utility preference differences, Med. Decision Making 12 (1992) 4 Abstract. 